\title{
Impact of BRAF, MLHI on the incidence of microsatellite instability high colorectal cancer in populations based study
} Hassan Brim ${ }^{1}$, Pooneh Mokarram 2,3, Fakhraddin Naghibalhossaini ${ }^{2,3}$, Mehdi Saberi-Firoozi ${ }^{2,3}$, Mansour Al-Mandhari ${ }^{4}$, Kamla Al-Mawaly ${ }^{4}$, Rayhaneh Al-Mjeni ${ }^{4}$, Abeer Al-Sayegh ${ }^{4}$, Sandy Raeburn ${ }^{4}$, Edward Lee ${ }^{5}$, Francis Giardiello ${ }^{6}$, Duane T Smoot ${ }^{1}$, Alexander Vilkin ${ }^{7}$, C Richard Boland ${ }^{7}$, Ajay Goel ${ }^{7}$, Mitra Hafezi ${ }^{1}$, Mehdi Nouraie ${ }^{1}$ and Hassan Ashktorab*1

Address: ${ }^{1}$ Department of Medicine and Cancer Center, Howard University, Washington, D.C, USA, ${ }^{2}$ Biochemistry Department, Shiraz University Medical Sciences, Shiraz, Iran, ${ }^{3}$ Gastroentrology Division, Shiraz University Medical Sciences, Shiraz, Iran, ${ }^{4}$ Department of Medicine, Sultan Qaboos University, Muscat, Oman, ${ }^{5}$ Department of Pathology, Howard University, Washington, D.C, USA, ${ }^{6}$ Department of Medicine, The Johns Hopkins University, Baltimore, Maryland, USA and ${ }^{7}$ Department of Medicine and Cancer Center, Baylor University Medical Center, Dallas, Texas, USA

Email: Hassan Brim - hbrim@howard.edu; Pooneh Mokarram - pmokarram@howard.edu;

Fakhraddin Naghibalhossaini - Naghibalhossaini@yahoo.com; Mehdi Saberi-Firoozi - Saberi-Firoozi@yahoo.com; Mansour Al-Mandhari - AlMandhari@squ.edu; Kamla Al-Mawaly -not@valid.com; Rayhaneh Al-Mjeni -Al-Mjeni@squ.edu; Abeer Al-Sayegh - Al-Sayegh@squ.edu;

Sandy Raeburn - Raeburn@squ.edu; Edward Lee - elee@howard.edu; Francis Giardiello - Giardiello@jhk.edu;

DuaneT Smoot - dsmoot@howard.edu; Alexander Vilkin - Vilkin@baylor.edu; C Richard Boland - Boland@baylor.edu;

Ajay Goel - Goel@baylor.edu; Mitra Hafezi - Hafezi@yahoo.edu; Mehdi Nouraie - Nouraie@howard.edu;

Hassan Ashktorab* - hashktorab@howard.edu

* Corresponding author

Published: 2I August 2008

Molecular Cancer 2008, 7:68 doi:10.1186/1476-4598-7-68
Received: 4 February 2008

Accepted: 2I August 2008

This article is available from: http://www.molecular-cancer.com/content/7/1/68

(c) 2008 Brim et al; licensee BioMed Central Ltd.

This is an Open Access article distributed under the terms of the Creative Commons Attribution License (http://creativecommons.org/licenses/by/2.0), which permits unrestricted use, distribution, and reproduction in any medium, provided the original work is properly cited.

\begin{abstract}
We have identified an alternative pathway of tumorigenesis in sporadic colon cancer, involving microsatellite instability due to mismatched repair methylation, which may be driven by mutations in the BRAF gene (V600E). Colorectal cancer (CRC) is the most common cancer in the world, and African Americans show a higher incidence than other populations in the United States. We analyzed sporadic CRCs in Omani (of African origin, $N=61$ ), Iranian (of Caucasian origin, $N=53$ ) and African American $(\mathrm{N}=95)$ patients for microsatellite instability, expression status of mismatched repair genes (hMLHI, hMSH2) and presence of the BRAF (V600E) mutation. In the Omani group, all tumors with BRAF mutations were located in the left side of the colon, and for African Americans, 88\% [7] of tumors with BRAF mutations were found in the right side of the colon. In African Americans, $31 \%$ of tumors displayed microsatellite instability at two or more markers (MSI-H), while this rate was $26 \%$ and $13 \%$ for tumors in the Iranian and Omani groups, respectively. A majority of these MSI-H tumors were located in the proximal colon (right side) in African American and Iranian subjects, whereas most were located in the distal colon (left side) in Omani subjects. Defects in $\mathrm{hMLHI}$ gene expression were found in $77 \%$ of MSI-H tumors in both African Americans and Iranians and in $38 \%$ of tumors in Omanis. BRAF mutations were observed in all subjects: $10 \%$ of tumors in African Americans (8/82), $2 \%$ of tumors in Iranians $(1 / 53)$, and 19\% of tumors in Omanis (1I/59). Our findings suggest that CRC occurs at a younger age in Omani and Iranian patients, and these groups showed a lower occurrence of MSI-H than did African American patients. Our multivariate model suggests an important and significant role of hMLHI expression and BRAF mutation in MSI-H CRC in these populations. The high occurrence of MSI-H tumors in African Americans may have significant implications for treatment, since patients with MSI$\mathrm{H}$ lesions display a different response to chemotherapeutic agents such as 5 -fluorouracil.
\end{abstract}




\section{Introduction}

Colorectal cancer (CRC) is the second leading cause of cancer-related deaths in the United States, despite recent improvements in the diagnosis and treatment of the disease [1]. The incidence and mortality rate of CRC are higher in African Americans than in the general population $[1,2]$. Many epidemiological and genetic investigations have focused on African Americans [2-4] with the goal of deciphering the reasons for such disparities. While socio-economic factors are likely involved (e.g., African Americans tend to reach more advanced stages of disease before diagnosis), biological factors also contribute to the disparity [5]. Dietary and environmental factors certainly play an important role, as Japanese immigrants to the US show higher colon cancer rates than do Japanese people living in Japan. The latter also started showing higher rates of colon cancer along with the westernization of their diets $[6,7]$.

The recent approval by the FDA of Bidil, a drug for heart failure in African Americans, illustrates ethnical/racial genetic specificities that lead to different interactions with a given drug or molecule [8]. Only limited genetic and epigenetic studies exist from Africa and other continents, including Asia, that have populations known to be of African descent. In Oman, some tribes have Bedouin roots and others have Asian and/or African origins [9]. In general, the Omani population has Asian and African ethnicities [10]. Other ethnic groups in Asia are not considered to be of African descent, such as Caucasian people in Iran. In this study, we used samples from patients treated for CRC in Oman, Iran and the US (African Americans) for genetic and epigenetic investigation. We chose these three populations based on their similarities and differences in African ethnicity [10-14].

Colon cancer develops through different pathways, all involving changes at the chromosomal or genetic levels. Other modifications occur epigenetically and affect the level of expression of certain targeted genes that are essential for the normal control of cell division within the colon mucosa [15]. It is now widely accepted that sporadic colorectal cancers frequently arise from pre-neoplastic lesions through the activation of oncogenes (K-ras, BRAF) and the inactivation of tumor suppressor genes (APC, p53, DCC) and mismatch repair (MMR) genes (MLH1 and MSH2) $[16,17]$. Also, activating mutations in $\mathrm{BRAF}$, one of the RAF genes which encode kinases that are regulated by Ras and mediate cellular responses to growth signals, have been found to be associated with MSI-H cancers [18]. The DNA MMR process can be impeded by genes that are either mutated [19] or silenced [4], leading to the expression of non-functional proteins or to a lack of expression, respectively. MMR pathway is primarily responsible for colon cancer development in families with
Hereditary Non Polyposis Colon Cancer (HNPCC), which represents about $5 \%$ of the generally inventoried colon cancer cases [20].

In the present study, we analyzed samples from two different populations of African descent (African American and Omani) and a Caucasian population (Iranian) for microsatellite instability and BRAF mutations. We correlated our findings with the silencing of genes involved in DNA MMR. We evaluated and compared the demographic and clinicopathological data in relation to molecular alterations in specific genes (BRAF, DNA MMR) to improve our understanding of colon tumorgenesis in people living in different environments.

\section{Methods \\ Patients}

A total of 95 African American CRC patients (from Howard University and Johns Hopkins Hospital between 1997 and 2004; self-identified as African American), 61 Omani CRC patients (from the two tertiary referral hospitals in Oman Sultan Qaboos University Hospital and the Royal Hospital between 2000 and 2004 who underwent surgical resection) and 53 Iranian CRC patients (from the two referral hospitals in Shiraz, Iran Namazi Hospital and Saadi Hospital) were included in this study. Formalinfixed, paraffin-embedded archival tissue was collected (with approval from all above sites' Institutional Review Boards) and clinical data was obtained (including race, age, site of primary tumor, mucin production and tumor differentiation). In addition, the family history of cancer was analyzed to identify those pedigrees that met either the Amsterdam I or Amsterdam II criteria for HNPCC. The study was performed on unselected and serially collected specimens. All cases underwent surgery within the given collection.

\section{DNA isolation and MSI analysis}

Archived and fresh tumor blocks were cut into 5- $\mu \mathrm{m} \mathrm{sec-}$ tions on Superfrost slides (Fisher Scientific, Pittsburgh, PA). The tumor and normal area were diagnosed by a pathologist using the $H \& E$ matched slide and microdissected to pinpoint the tumor areas as well as normal areas from at least two slides. A pinpoint DNA extraction kit was used as recommended by the manufacturers (Zymo Research). The extracted tumor and normal matched DNA were used as template in PCR reactions where five microsatellite markers (Cancer Research 58:5248-5257, 1998;[21]; BAT25, BAT26, D17S250, D5S346 and D2S123) were used to evaluate MSI status. PCR products were analyzed in a $3130 \mathrm{ABI}$ GeneScan. Those displaying DNA instability at only one of the markers (including the dinucleotides) were labeled MSI-L, those displaying instability with two or more markers were labeled MSI-H, and those displaying no instability with any of the five mark- 
ers tested were labeled MSS. Due to unclear characteristics of MSI-L, we combined MSS and MSI-L as one group (non-MSI-H).

\section{Methylation-specific PCR}

The presence or absence of hMLH1 and p16 methylation in cancers was determined by comparing the signals from tumor-derived tissues with those from normal, non-cancerous tissues, as previously described $[3,4]$. DNA was extracted from the samples using a Gentra DNA extraction kit (Gentra) and was modified using DNA modification kits as recommended by the manufacturers (Zymo Research). MSP was used to distinguish unmethylated from methylated alleles, based on sequence alterations produced by bisulfite treatment of DNA, to convert unmethylated cytosines to uracil. These changes are identified by subsequent PCR using primers specific to the methylated (unchanged) or unmethylated (changed) DNA. Briefly, $1 \mu \mathrm{g}$ of genomic DNA was denatured by treatment with $\mathrm{NaOH}$ and was modified by the addition of sodium bisulfite. DNA samples were purified using Wizard DNA purification resin according to the manufacturer's instructions (Promega). These DNA samples were again treated with $\mathrm{NaOH}$, then precipitated with ethanol and resuspended in water. PCR reactions were performed using the primer pairs described below in the following reaction mix: $10 \times$ PCR buffer [16.6 $\mathrm{mM}$ ammonium sulfate, $67 \mathrm{mM}$ Tris (pH 8.8), $6.7 \mathrm{mM} \mathrm{MgCl} 2$, and $10 \mathrm{mM} 2$ mercaptoethanol], dNTPs (each at $1.25 \mathrm{mM}$ ), primers (50 pmol each per reaction), and bisulfite-modified DNA (50 $\mathrm{ng}$ ) in a final volume of $50 \mu \mathrm{l}$. Reactions were hot-started at $95^{\circ} \mathrm{C}$ for $5 \mathrm{~min}$, after which 1.25 units of Taq polymerase (Life Technologies, Inc.) were added. Amplification was carried out in an Applied Biosystem temperature cycler for 40 cycles $\left(30 \mathrm{sec}\right.$ at $95^{\circ} \mathrm{C}, 30 \mathrm{sec}$ at $59^{\circ} \mathrm{C}$ then $30 \mathrm{sec}$ at $72^{\circ} \mathrm{C}$ ), followed by a final 4 -min extension at $72^{\circ} \mathrm{C}$. Two sets of primers were used simultaneously to check for methylated or unmethylated $\mathrm{CpG}$ islands at the level of hMLH1 and $\mathrm{p} 16$ promoters. The primer sequences were as in our previous study [4]. Controls for methylated and unmethylated DNA were DNA from the SW48 colon cancer cell line and normal lymphocytes, respectively. Each PCR reaction product $(10 \mu \mathrm{l})$ was directly loaded into a $2 \%$ agarose gel, which was later stained with ethidium bromide to allow DNA visualization under UV illumination. The presence of a band in unmethylated tumor and matched normal with the absence of a methylation band in the tumor was defined as unmethylated. However, when a methylated band was present for tumor and absent for the normal, we defined the sample as methylated (or semi-methylated if both unmethylated or methylated bands were present in the tumor).

\section{Histopathological analysis}

Independent pathologists who were unaware of the MSI status of any of the samples evaluated specific histopatho- logical characteristics. Grading of tumors was achieved by staining with Hematoxylin-Eosin (H\&E). Tumors were classified as proximal (proximal to the splenic flexure) or distal. The TNM system of the International Union against cancer was used for tumor staging. Mucin production was evaluated using the modified criteria of Wiggers et al, [22] and reported as absent (no extracellular mucin production), focal (when extracellular mucin production was present in $<50 \%$ of the cells) or predominant (when the area of extra cellular mucin production was present in $\geq$ $50 \%$ of the cells).

\section{Immunohistochemistry}

Tissue obtained from paraffin-embedded blocks was used for the immunohistochemistry experiments. Sections (5 $\mu \mathrm{m}$ ) were mounted on charged glass slides, deparaffinized with xylene for $2 \times 10 \mathrm{~min}$ and rehydrated using a graded ethanol series. Antigen retrieval was performed by placing the samples in a microwave oven for $12 \mathrm{~min}$, with occasional interruption to avoid tissue degradation by excessive heat. The slides were then treated with hydrogen peroxide, followed by incubation with the primary and secondary antibodies, a streptavidin-biotin complex, an amplification reagent, streptavidin-peroxidase and substrate-chromogen solution using the Envision system according to the manufacturers' protocol (DAKO). The samples were then counterstained with hematoxylin, rinsed with ethanol, dried and visualized by a light microscopy. Tissue samples to which no primary antibody had been added were used as negative controls. All immunohistochemistry reagents were purchased from DAKO (Carpinteria, CA) and the antibodies (hMLH1 clone G168-15, 1/100 dilution and hMSH2 clone 556349, 1/ 500 dilution) were purchased from PharMigen (San Diego, CA). The slides were read by pathologists unaware of the MSI status. Absence of MLH1 and MSH2 nuclear expression was defined as negative staining.

\section{BRAF mutation analysis}

Samples were analyzed for the presence of a point mutation that frequently takes place in the oncogene BRAF, leading to the change of valine into glutamic acid at position 600 of the BRAF protein. DNA from the analyzed samples was used as a template in PCR reactions using two BRAF primers encompassing BRAF exon 15 where the above substitution is known to take place. Amplified fragments were analyzed by sequencing in a $3130 \mathrm{ABI}$ GeneScan to confirm the presence of the mutation.

\section{Statistical analysis}

The MSI phenotypes were divided into two groups: nonMSI (MSS+MSI-L) and MSI-H (two or more markers unstable). Age of patients was a continuous variable, while the stage of the cancer, gender, location, mucin production, differentiation, and hMLH1 and hMSH2 methylation were categorical variables. For statistical analysis, 
mucin production was categorized as 0 (no production), $<50 \%$ or $\geq 50 \%$. The distributions of categorical variables were shown by frequency table, and for age by computing mean (SD). We tested the distribution of categorical variables between MSI-H and non MSI-H groups by asymptotic Chi-Square or the Fisher's-Exact test, as appropriate and computing of OR $(95 \% \mathrm{CI})$. The age difference between two groups was tested by student $t$ test. The univariate analysis was done for both races separately. We selected race, age (as a continuous variable), differentiation, tumor site (right vs. left), stage [1-4], BRAF mutation, hMHL1 and hMSH2 expression (positive vs. negative), and P16 and hMHL1 methylation to enter to a Backward logistic regression model, with MSI as a dependent variable. Univariate analysis showed evidences of interaction between race and some markers, so we developed a model, with interaction terms. Then a final model was developed with the variables with significant effect $(\mathrm{p}<$ 0.05 ) on the risk of MSI-H including interaction term. All analysis was performed by the SPSS program 15.0 (Chicago, IL).

\section{Results}

Distinct clinicopathological features according to MSI status and tumor Site

The clinical and pathological characteristics of the patients are presented in Table 1, 2, 3. For MSI experiments, we analyzed samples from 95 African American patients, (56 females, 39 males). The mean (SD) age of the African American patients (at the time of tissue collection) was 65.7 [15] years. Of the 95 analyzed African American samples, 29 (30.5\%) were MSI-H, and 66

Table I: Clinicopathological and genetic characteristics of AA CRC cases

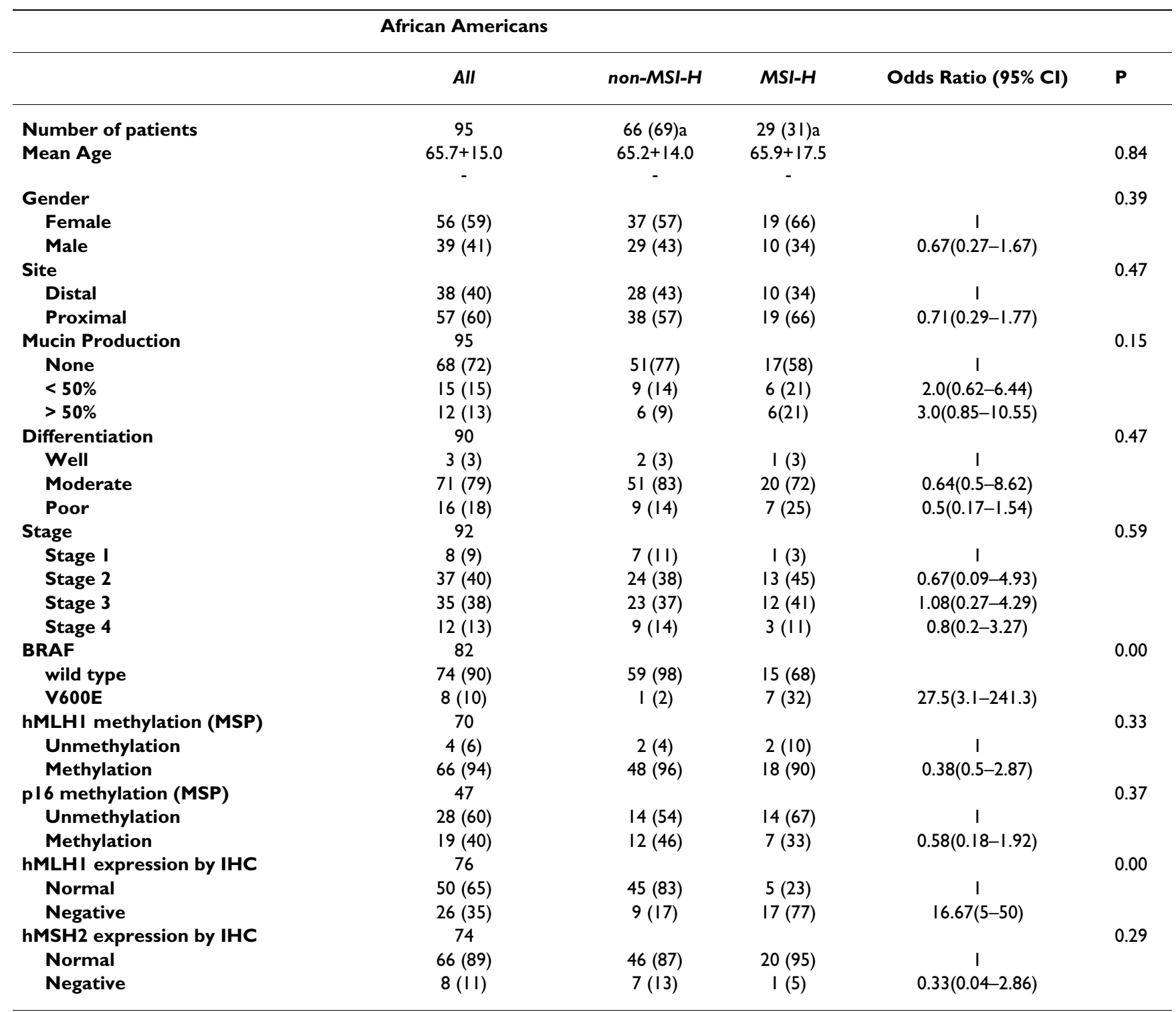


Table 2: Clinicopathological and genetic characteristics of Iranian CRC cases.

\begin{tabular}{|c|c|c|c|c|c|}
\hline & Iranian & & & & \\
\hline & All & non-MSI-H & MSI-H & Odds Ratio & $\mathbf{P}$ \\
\hline Number of patients & 53 & $39(74) \mathrm{a}$ & $14(26) \mathrm{a}$ & & \\
\hline \multirow[t]{2}{*}{ Mean Age } & $59.8+12.7$ & $59.9+12.7$ & $59.4+13.1$ & & 0.90 \\
\hline & - & - & - & & \\
\hline Gender & 53 & & & & 0.52 \\
\hline Female & $19(36)$ & $13(33)$ & $6(43)$ & I & \\
\hline Male & $34(64)$ & $26(67)$ & $8(57)$ & $0.67(0.19-2.33)$ & \\
\hline Site & 53 & & & & 0.00 \\
\hline Distal & $40(76)$ & $37(95)$ & $3(2 I)$ & I & \\
\hline Proximal & $13(24)$ & $2(5)$ & II(79) & $66.67(10-500.00)$ & \\
\hline Mucin Production & NA & & & & \\
\hline None & NA & & & & \\
\hline$<\mathbf{5 0 \%}$ & NA & & & & \\
\hline$>\mathbf{5 0} \%$ & NA & & & & \\
\hline Differentiation & 53 & & & & 0.00 \\
\hline Well & $29(54)$ & $26(67)$ & $3(22)$ & I & \\
\hline Moderate & $22(42)$ & $13(33)$ & $9(64)$ & $6(1.38-26.00)$ & \\
\hline Poor & $2(4)$ & 0 & $2(14)$ & NA & \\
\hline Stage & 53 & & & & 0.67 \\
\hline Stage I & 0 & 0 & 0 & NA & \\
\hline Stage 2 & $12(23)$ & $10(26)$ & $2(14)$ & I & \\
\hline Stage 3 & $37(70)$ & $26(67)$ & II(79) & $0.60(0.04-9.16)$ & \\
\hline Stage 4 & $4(7)$ & $3(7)$ & $\mathrm{I}(7)$ & $1.27(0.12-13.58)$ & \\
\hline BRAF & 53 & & & & 0.09 \\
\hline Wild type & $52(98)$ & $39(100)$ & $13(93)$ & & \\
\hline V600E & $I(2)$ & 0 & $I(7)$ & NA & \\
\hline hMLHI methylation (MSP) & 53 & & & & 0.00 \\
\hline Unmethylation & $42(79)$ & $38(97)$ & $4(29)$ & I & \\
\hline Methylation & $I I(2 I)$ & $I(3)$ & $10(71)$ & $95.00(9.53-946.94)$ & \\
\hline pl6 methylation (MSP) & 53 & & & & 0.00 \\
\hline Unmethylation & $45(85)$ & $38(97)$ & $7(50)$ & I & \\
\hline Methylation & $8(15)$ & $\mathrm{I}(3)$ & $7(50)$ & $38.00(4.03-358.74)$ & \\
\hline hMLHI expression by IHC & 25 & & & & 0.00 \\
\hline Normal & $15(60)$ & $12(100)$ & $3(23)$ & & \\
\hline Negative & $10(40)$ & 0 & $10(77)$ & NA & \\
\hline hMSH2 expression by IHC & 25 & & & & 1.00 \\
\hline Normal & $24(96)$ & $12(100)$ & $12(92)$ & & \\
\hline Negative & I(4) & 0 & I(8) & NA & \\
\hline
\end{tabular}

(69.5\%) were non-MSI-H (Table 1). Four MSI-H patients had a strong family history of colon cancer, and met the Amsterdam criteria for HNPCC. Thirteen other patients met the Bethesda criteria [23], based on the age at diagnosis of CRC; however, tissue samples from thirteen of these patients were non-MSI-H. Sixty-one tissue samples from the Omani patients were analyzed ( 24 females, 37 males; mean age (SD) was 52.7 (13.6). MSI analysis showed that $53(86.9 \%)$ of Omani samples were non-MSI-H, and 8 (13.1\%) were MSI-H (Table 2). From this group, five patients that were MSI-H had a strong family history of colon cancer meeting the Amsterdam criteria for HNPCC. Nineteen other patients met the Bethesda criteria [23], based on the age at diagnosis of CRC; however, tissue samples from fourteen of these patients were non-MSI-H.
Fifty-three tissue samples from Iranian patients were analyzed (64\% female; mean age (SD) in Iranian patients was 59.8 (12.7; Table 3). Fourteen (26\%) of the Iranian samples were MSI-H tumors. The HNPCC and Familial Adenoma Polyposis were not seen in Iranian patients in this study. In the Omani and Iranian populations, there were more MSI-H tumors in males than females $(75 \%$ vs $25 \%$ in Omani; $57 \%$ vs. $43 \%$ in Iranian); in the African American group, there were more MSI-H tumors in females (66\% vs 34\%). However, these gender differences were insignificant trends.

A total of $57(60 \%)$ primary African American tumors were located in the proximal colon and $40 \%$ [38] were distal. Within the MSI-H group, 19 (66\%) were proximal 
Table 3: Clinicopathological and genetic characteristics of Omani CRC cases.

\begin{tabular}{|c|c|c|c|c|c|}
\hline & Omani & & & & \\
\hline & All & non-MSI-H & MSI-H & Odds Ratio & $\mathbf{P}$ \\
\hline Number of patients & 61 & $53(87) a$ & $8(13) a$ & & \\
\hline \multirow[t]{2}{*}{ Mean Age } & $52.7+13.6$ & $53.1+12.8$ & $51.5+19.2$ & & 0.76 \\
\hline & - & - & - & & \\
\hline Gender & & & & & 0.37 \\
\hline Female & $24(39)$ & $22(42)$ & $2(25)$ & I & \\
\hline Male & $37(61)$ & $3 I(58)$ & $6(75)$ & $2.12(0.39-11.55)$ & \\
\hline Site & 61 & & & & 0.75 \\
\hline Distal & $5 \mathrm{I}(84)$ & $44(83)$ & $7(87)$ & I & \\
\hline Proximal & $10(16)$ & $9(17)$ & $\mathrm{I}(13)$ & $1.43(0.16-13.11)$ & \\
\hline Mucin Production & 61 & & & & 0.44 \\
\hline None & $47(77)$ & $42(78)$ & $5(63)$ & I & \\
\hline$<\mathbf{5 0 \%}$ & $14(23)$ & II (20) & $3(37)$ & $2.3(0.47-11.10)$ & \\
\hline$>\mathbf{5 0} \%$ & 0 & 0 & 0 & NA & \\
\hline Differentiation & 60 & & & & 0.44 \\
\hline Well & $7(12)$ & $7(14)$ & 0 & NA & \\
\hline Moderate & $49(82)$ & $43(81)$ & $6(86)$ & 1 & \\
\hline Poor & $4(6)$ & $3(6)$ & I (14) & $2.39(0.21-26.84)$ & \\
\hline Stage & 61 & & & & 0.28 \\
\hline Stage I & I (2) & I (2) & 0 & NA & \\
\hline Stage 2 & $20(33)$ & $15(28)$ & $5(62)$ & 1 & \\
\hline Stage 3 & $31(50)$ & $29(55)$ & $2(25)$ & $0.2 \mathrm{I}(0.02-1.50)$ & \\
\hline Stage 4 & $9(15)$ & $8(15)$ & $\mathrm{I}(13)$ & $0.38(0.01-4.4 I)$ & \\
\hline BRAF & 59 & & & & 0.62 \\
\hline Wild type & $48(81)$ & $42(82)$ & $6(75)$ & 1 & \\
\hline V600E & $11(19)$ & $9(18)$ & $2(25)$ & $1.56(0.27-9.0)$ & \\
\hline hMLHI methylation (MSP) & 49 & & & & 0.47 \\
\hline Unmethylation & $8(16)$ & $6(14.6)$ & $2(25)$ & 1 & \\
\hline Methylation & $41(84)$ & $35(85.4)$ & $6(75)$ & $0.5 \mathrm{I}(0.08-3.17)$ & \\
\hline p I6 methylation (MSP) & 44 & & & & 0.09 \\
\hline Unmethylation & $27(62)$ & $20(56)$ & $7(88)$ & I & \\
\hline Methylation & $17(38)$ & $16(44)$ & $\mathrm{I}(12)$ & $0.18(0.02-1.61)$ & \\
\hline hMLHI expression by IHC & 61 & & & & 0.68 \\
\hline Normal & $42(69)$ & $37(70)$ & $5(62)$ & 1 & \\
\hline Negative & $19(32)$ & $16(30)$ & $3(38)$ & $1.39(0.29-6.67)$ & \\
\hline hMSH2 expression by IHC & 61 & & & & 0.63 \\
\hline Normal & $56(92)$ & $49(92)$ & $7(87)$ & I & \\
\hline Negative & $5(8)$ & $4(8)$ & $\mathrm{I}(13)$ & $1.75(0.17-16.67)$ & \\
\hline
\end{tabular}

Parentheses indicate percentages: All values are based on column except ${ }_{\mathrm{a}}$ based on row. $\mathrm{MSP}=$ methylation-specific PCR; IHC = immunohistochemistry

and 10 (34\%) were distal (Table 1). The non-MSI-H group showed a distribution with $38(57 \%)$ proximal tumors and $28(43 \%)$ distal tumors. Mucin production was noted in 27 tumors including $12 \mathrm{MSI}-\mathrm{H}$ and 15 non-MSI-H tumors. Fifty-one of the Omani tumors were located in the distal colon $(84 \%)$. The prevalence of distal lesions in the MSI-H group was $87 \%$. Of the 61 Omani samples, 47 $(77 \%)$ showed no mucin production, $14(23 \%)$ had focal mucin production (Table 2). The percentage of lesions that produced mucin was $20 \%$ and $37 \%$ for MSI-H and Non-MSI-H, respectively. Frequency of proximal tumors in Iranian patients was $13(24 \%)$ and the prevalence of proximal lesions in the MSI-H group was 79\% [11]. In univariate analysis, a proximal location increases the rate of MSI-H in Iranian patients significantly $(\mathrm{OR}=$ 66.67(10-500)) $(\mathrm{p}=0.001$; Table 3)).
The majority of tumors were found to be moderately differentiated in African Americans (79\%) and Omanis $(82 \%$; Table 1,2$)$. Iranian tumors were mostly well differentiated (54\%). The percentage of moderately differentiated tumors was $86 \%$ in the MSI-H Omani group compared with $72 \%$ in African Americans and 64\% in Iranians (Table 1,3 ). In addition, seven and one MSI-H tumors showed poor differentiation in African Americans and Omanis, respectively. While in African Americans, one MSI-H was well differentiated, no patient in Iranian non-MSI-H cases was poorly differentiated (Table 1, 3). The difference was insignificant trend in African Americans and Omanis but in Iranian patients differentiation was significantly correlated with MSI-H occurrence. This finding was not sustained in multivariate analysis. 
Most of the patients in the series were stage II or higher (Table 1, 2, 3), with 45\% [13] of African American, 62\% [5] of Omani, and 14\% [2] of Iranian MSI-H lesions at stage II. Thirty-eight percent [24] of African American, $28 \%$ [15] of Omani, and 23\% [12] of Iranian of the nonMSI-H lesions were at stage II (Table 3). Forty-one percent [12] of African American, 25\% [2] of Omani, and 79\% [11] of Iranian of the MSI-H lesions were at stage III (Table 1, 2, 3). Thirty-seven percent [23] of African American, 55\% [29] of Omani, and 67\% [26] of Iranian of the non-MSI-H lesions were at stage III. Fourteen percent [9] of African American, 15\% [8] of Omani, and 7\% [3] of Iranian of the non-MSI-H lesions were at stage IV (Table 1, 2, 3 ). There was insignificant trend in the stage of the lesions between the MSI and non-MSI-H groups.

\section{Correlation between methylation pattern of the hMLHI promoter and MSI status}

Among MSI-H samples, hMLH1 promoter methylation was found in 90\% [18] of African American, 75\% [6] of Omani and $71 \%$ [10] of Iranian tumors, confirming a previous finding of predominant methylation of these genes of the promoter in Africans (Table 1, 2, 3) [3,4]. Non-MSI$\mathrm{H}$ tumors in both African Americans and Omani tumors showed methylation of the hMLH1 promoter as well (> $80 \%$ ). In Iranian non-MSI-H patients, the frequency of hMLH1 methylation was 3\% [1]. The methylation status of hMLH1 does not seem to be gender- or stage-specific. In multivariate analysis, including the interaction terms, the hMLH1 methylation has a significant effect on MSI-H occurrence $(\mathrm{OR}=13.84(1.05-182.72) ; \mathrm{p}=0.046)$ (Table 4). In MSI-H tumors, p16 methylation occurred in 33\% [7] of African American, 12\% [1] of Omani and 50\% [7] of Iranian tumors. While it was more than $40 \%$ in nonMSI-H tumors in African Americans and Omani patient populations, this figure was 3\% [1] in Iranian non-MSI-H CRC patients.

Table 4: Multivariate analysis for the risk factors associated with MSI-H occurrence (Model including single term and interactions effect)

\begin{tabular}{lcc}
\hline Factor & OR $(95 \% \mathrm{Cl})$ & P value \\
\hline Normal hMLHI expression by IHC & $0.13(0.04-0.4 I)$ & $<0.000 \mathrm{I}$ \\
BRAF V600E mutation & $\mathrm{I} 2.1 \mathrm{I}(2.82-52.03)$ & $0.00 \mathrm{I}$ \\
hMLHI methylation & $\mathrm{I} .84(1.05-182.72)$ & 0.046 \\
Race & $\mathrm{I}$ & 0.946 \\
$\quad$ African-Americans & $0.83(0.04-0.18 .30)$ & 0.905 \\
$\quad$ Omani & $0.68(0.07-6.58)$ & 0.739 \\
$\quad$ Iranian & & 0.072 \\
hMLHI methylation* Race & $0.04(0.01-1.74)$ & 0.091 \\
hMLHI methylation* Omani & $0.02(0.01-0.63)$ & 0.032 \\
hMLHI methylation* Iranian & & \\
\hline
\end{tabular}

* indicates the interaction term between two variables.

\section{Correlation between $\mathrm{hMLHI}$ protein expression and MSI status}

Expression of the hMLH1 and hMSH2 nuclear proteins was examined immunohistochemically in paraffinembedded tissue sections [4]. In all cases, non-neoplastic cells displayed positive nuclear staining for both hMLH1 and hMSH2. The nuclear stained slides were read by two different pathologists, and normal tissue on slides where no primary antibody stained was used as negative control. In total, 76 African American, 61 Omani, and 25 Iranian cases were analyzed. Thirty-five and $11 \%$ of African American tumors assayed showed loss of staining for hMLH1 and hMSH2, respectively. Moreover, loss of hMLH1 and hMSH2 staining was observed in $77 \%$ and $5 \%$ of MSI-H African American tumors, respectively (Table 1). The loss of hMLH1 and hMSH2 staining was observed in $17 \%$ and $13 \%$ of non-MSI-H African American tumors, respectively (Table 1). In Omani tumors: $38 \%(\mathrm{n}=3)$ of the MSI-H tumors showed absences of hMLH1 expression (Table 2); $30 \%(\mathrm{n}=16)$ of the non-MSI-H tumors had negative hMLH1. Fifty-six cases of Omani patient tested for the presence of hMSH2 protein by immunohistochemical staining, seven Omani cases were MSI-H. In Iranian patients, $77 \%$ [10] of the MSI-H tumors were negative for hMLH1 expression (Table 3); all of non-MSI-H tumors were positive for hMLH1 expression, while for hMSH2 these figures were $8 \%[1]$ and 0 , respectively. In multivariate analysis, including the interaction terms, the hMLH1 expression has a significant preventive effect on MSI-H occurrence $(\mathrm{OR}=0.13(0.04-0.41) ; \mathrm{p}<0.0001$; (Table $4)$ ).

\section{Correlation between BRAF mutation and MSI status}

Samples were analyzed for the presence of a point mutation that frequently occurs in the oncogene BRAF leading to the change of valine to glutamic acid at position 600 of the BRAF protein. In all samples only $10 \%$ [8] African American, 19\% [11] Omani and 2\% [1] Iranian samples displayed the mutation by sequencing (Table $1,2,3$ ). In the MSI-H group, the BRAF mutation was 32\% [7] in African Americans, 25\% [2] in Omani, and 7\% [1] in Iranian, respectively. Eighteen percent and $2 \%$ of non-MSI-H tumors carry the BRAF mutation in African Americans and Omanis, respectively, while none of the Iranians carried a BRAF mutation in this group. A BRAF mutation is a significant risk factor for MSI-H occurrence even after controlling for other factors in the multivariate model $(\mathrm{OR}=$ 12.11(2.82-52.03); $\mathrm{p}=0.001$; (Table 4)).

\section{Discussion}

DNA MMR gene silencing and/or mutation are the main factors leading to accumulation of mutations within genes and general genome instability [19]. The MSI phenotype resulting from such alterations is one of the early events leading to the development of certain cancers. It occurs in 
patients with Lynch syndrome and in those that acquire such alterations somatically [24]. Another event occurring in adenoma polyp is mutation in oncogenes, specifically in K-ras and BRAF genes in the case of colon cancer [2426]. The linkage between BRAF mutations and MSI was previously reported [27-30]. In general, Omani people have a mixed Asian and African ethnic background [10] and Iranians are of Caucasian ethnicity. Here we demonstrate that in African Americans, Omanis and Iranians, the MSI phenotype occurs in $31 \%, 26 \%$ and $13 \%$ of CRC tumors, respectively. In addition, the locations of the tumors in African Americans and Iranians were primarily proximal compared to distal for Omanis; and BRAF mutations were more prevalent in Omanis than African Americans or Iranians (19\%, $10 \%$ and $2 \%$, respectively). While the MSI phenotype in this sample of African Americans is less than we previously reported (43-45\%), [3,4] it appears to be more prevalent in African Americans than in others and still high in the general US population [31-33]. The current sample contained more African Americans and more right-sided than left-sided tumors. The MSI phenotype was more common in proximal tumors than in distal ones ( $p=0.47)$, strengthening earlier findings of such an association [31-33]. The prevalence of MSI-H tumors indicates the importance of BRAF mutations, particularly in the African Americans, since they represent a higher mutation profile than Iranians and Omanis. This finding suggests that, at least within the MSI-H group of patients, the BRAF V600E mutation in exon 15 is the major event leading to tumor development. In addition, the distal location of Omani MSI-H tumors may also play an important role in the presentation of the disease compared to proximal ones in the African American and Iranian populations. The lower frequency of MSI-H tumors observed in Omani patients could be related to the higher frequency of the distal location. This needs to be verified in a larger sample size.

The absence of hMLH1 expression was more pronounced in MSI-H tumors from African American and Iranian patients $(77 \%$ of tumors in these groups showed no hMLH1 expression). However, for Omanis, the moderate hMLH1expression (62\%) in MSI-H may indicate some other defects in the component of base excision repair (Oxidative DNA damaged markers such as 8-hydroxyguanosine), or distinct lymphangiogenic phenotype associated with MSI other than in mismatch repair genes. The tumors that we have studied included MSI-H tumors that were negative using immunohistochemistry for hMLH1. This incidence is less than compared to that described in the literature $(77 \%$ [34]), although the numbers described are small.

These results are in concordance with the MSP analysis showing that a majority of samples displayed methylation at the hMLH1 promoter. The methylation of hMLH1 is most likely from a specific genome methylation process in progression of colon cancer. The African American group was older than both the Omani and Iranian group. It has been demonstrated that older people, particularly those in the 7 th-9th decade of life, have a much higher chance of hypermethylation of hMLH1 and MSI. This is consistent with hMLH1 methylation in the African American cancers both in MSI-H and non-MSI cases. However, in Iranians, a higher profile of epigenetic silencing of hMLH1 may explain the MSI-H tumors but not in non-MSI. In addition, the distal location of Omani tumors may also play an important role in the presentation of the disease compared to the African American who has generally proximal CRC.

Our results demonstrate that methylation of hMLH1 is the major cause of MSI in sporadic CRC consistent with our previous findings $[3,4]$. The fact that the hMLH1 gene is methylated indicates that it may be inactivated by an epigenetic mechanism. The association of higher levels of CpG island methylation with more advanced histological changes suggests that $\mathrm{CpG}$ methylation plays a role in CRC [30]. However, the pathophysiology of hyper-methylation (the why, when and where) has yet to be elucidated. Cancers can be classified according to their degree of methylation. Those with high degrees of methylation (the CpG island methylator phenotype, or CIMP) represent a clinically and etiologically distinct group that is characterized by 'epigenetic instability'. The MSI-H and CIMP phenotype may explain the criteria in proximal tumors in African American and Iranian but not the distal ones in Omani tumors; however, the CpG island methylation status of a broader panel of genes needs to be investigated to determine whether this is the case. Some samples for MLH1 methylation failed to display MLH1 protein by immunohistochemistry and were non-MSI (MSS and MSI-L). Possible explanations might be that the targeted $\mathrm{CpG}$ island for methylation in this study is located upstream of the gene, and has a minor effect on the transcription of MLH1 protein [35] or that the detected methylation is only in a small cell population that does not reflect the overall tumor phenotype. Full methylation of the hMLH1 promoter region and subsequent gene inactivation may play a crucial role in carcinogenesis of MSI-H CRCs. Therefore, in our on-going investigation, we are studying the methylation status of the lesions by examining all CpG sites [36] especially within non-MSI tumors where data reveals lack of protein expression. Some non-MSI tumors were methylated at the MLH1 site and this may be due to the partial or hemimethylation at an altered MLH1 site. This is consistent with the lack of correlation of between the methylation status and level of expression of MLH1[37]. Indeed, more markers need to be considered to measure methylation in 
order to establish a methylation phenotype that correlates the protein expression status and allows for the understanding of preferential carcinogenic pathways. Positive staining was confirmed in adjacent normal tissue within the same slide validating of the staining for specimens that were found to be negative for either MLH1 or MSH2. In addition, preferential microsatellite loci containing large repeat units, but not loci containing mono- or dinucleotide repeats units, may contribute to the non-MSI tumors, particularly MSI-L CRC tumors.

Many explanations could account for the differences between African Americans and the other populations. The difference in MSI frequency might be due to genetic specificities or to behavioral/dietary causes [38]. Dietary factors such as folate, vitamins, and methionine may be associated with colon cancer because of involvement in DNA methylation and hence on the CpG island, MSI and BRAF. A recent study questioned the unique role for dietary folate, alcohol, vitamins $\mathrm{B}_{6}$ and $\mathrm{B}_{12}$ and methionine in the CIMP phenotype [39]. In addition, use of alcohol and obesity were associated with an increased risk of tumors that were MSI-H and CIMP-low (less than two markers methylated) [39]. The number of lymph nodes, distance organ metastases and additional impairment of the MMR system may associate with the more aggressive behavior of CRC in African Americans.

Studies have investigated the traditional (nonserrated) adenoma-carcinoma sequence and the serrated polyp neoplasia for BRAF and MSI. MSI-H was identified only in the adenocarcinoma component of serrated carcinomas $[40,41]$. BRAF mutation has been shown to be a specific marker for a serrated polyp pathway that has its origin in a hyperplastic polyp and a potential end point as MSI carcinoma. A recent study indicated that MSI-H in the sporadic colorectal cancers may be part of a clinically distinct subgroup with a high incidence of BRAF mutation developed from serrated polyps [26]. In this study we categorized the histological status of the end point such as carcinomas with residual adenoma, the serrated polyp neoplasia pathway and the traditional (nonserrated) adenoma-carcinoma sequence. However, we did not find any evidence of serrated or serrated hyperplastic tissue in the MSI-H tumors. Therefore, our BRAF and MSI-H analyses indicate that tumors may not belong to the serrated pathway, which needs additional investigation. Most hyperplastic polyps occur in the rectum and sigmoid colon, but most serrated (hyperplastic) polyps occur in the right colon and are associated with proximal cancers $[40,41]$. All but one (13\%) Omani, 79\% Iranian, 66\% of African American MSI-H tumors were proximal with no evidence of serrated hyperplastic polyps. Tumors in these populations were moderately differentiated with mixed adenomas. Therefore, at this time it is not clear whether or not mixed adenoma types have any role in the MSI-H in African Americans.

The population of the Sultanate of Oman is especially interesting because it represents a combination of African and Asian heritage in a small country with the distribution of CRC disease in young people, which may be due to the age structure of the population in Oman. The effect of environmental factors such as diet, physical activity, access to health care, frequent tribal marriage and lifestyle can not be ruled out for the occurrence of the CRC in young age $[9,10,42,43]$. The Iranian population is a large collection of ethnic groups and their descent were from ancient Iranian peoples[44]. Modern Persians themselves are also a heterogeneous group of peoples descended from various Caucasian peoples $[14,45]$. The younger age distribution of Iranian CRC disease also may be due to the age structure of the population. However, the effect of environmental factors such as diet and lifestyle can not be ruled out. Our data on CRC lead us to speculate the complex interactions of genotype, environmental factors (such as diet), and other lifestyle factors in the pattern of bowel cancer. Further epidemiology data to compare the age-specific incident rates for Oman, Iran and African American is needed to confirm this finding.

The proximal location of tumors in African Americans is consistent with the tumors in Western and Asian studies $[31-33,46,47]$ which may reflect the impact of western diets on the African Americans. However, the high MSI level for African Americans for this limited sample size may in part be due to the increased age of these patients along with finding the majority of the tumors on the right side of the colon. The Iranian tumors closely mimic what we see in Caucasians in the U.S., most tumors are left sided, most of the MSI-H tumors are right sided and the MSI-H tumors are associated with higher tumor differentiation. The distal location of the Omani tumors and the low MSI level is an important observation compared to the moderate and high proximal MSI level in Iranian and African American tumors, respectively. The alteration of K-RAS may also contribute to the methylator phenotype in CRC, especially in the Iranian tumors, which we plan to study in the future [30]. The rate of mutation and its level in MMR deficiency may contribute and determine the frameshift rate for the loss of these proteins in CRC, hence different behavior from these tumors.

All of these factors may contribute to the risk of colon cancer and presentation of the disease in African American, Omani and Iranian patients. We cannot rule out a genetic predisposition in these patients since we did not have access to detailed family history and, therefore, some of the subjects may have had genetic and epigenetic predispositions. In this study we did not use other groups such 
as white Americans, other Africans and Asian in our controls for any direct or indirect comparison analysis. We plan to have a more detailed study regarding the diversity of these populations since the scope of this study focused on the clinicopathological features.

In conclusion, this first comparative clinicopathological investigation in three different populations suggests that the MSI-H CRC phenotype in African American, Iranian and Omani patients is significantly associated with BRAF mutation and hMLH1 expression. CRCs in African Americans tend to be higher in microsatellite instability (32\%) and more often located in the proximal colon, compared to Iranian and Omani CRC tumors. The high level of MSI$\mathrm{H}$ in African Americans may have significant implications in treatment plans, because MSI-H lesions are often rightsided and may show a different response to chemotherapeutic agents such as 5-fluorourcil [48].

\section{Competing interests}

The authors declare that they have no competing interests.

\section{Authors' contributions}

HB carried out the MSI study. PM, FN, and MS recruited Iranian samples and run MSI and immunohistochemistry. MA, KAl-M, RAl-M, and AAl-S, and SR recruited Omani samples from different hospital in Oman and run methylation analysis. FG recruited samples from Johns Hopkins and performed the H\&E staining. DTS help in the sample recruitment and reviewing the data. from Howard university. AV, RCB and AG performed run the BRAF mutation analysis. EL, MH performed the pathological analysis, $\mathrm{MN}$ run the statistics. HA designed the experiment and data analysis. All authors read and approved the final manuscript.

\section{Acknowledgements}

This work was supported by Grant \#CA 10268I, funded by the National Cancer Institute, NIH, GCRC and Marcia Johnson award from Howard University.

\section{References}

I. Jemal A, Murray T, Ward E, Samuels A, Tiwari RC, Ghafoor A, Feuer EJ, Thun MJ: Cancer statistics, 2005. CA Cancer J Clin 2005, 55(I): $10-30$

2. Carethers JM: Racial and ethnic factors in the genetic pathogenesis of colorectal cancer. J Assoc Acad Minor Phys 1999, i 0(3):59-67.

3. Ashktorab H, Smoot DT, Carethers JM, Rahmanian M, Kittles R, Vosganian G, Doura M, Nidhiry E, Naab T, Momen B, Shakhani S, Giardiello FM: High incidence of microsatellite instability in colorectal cancer from African Americans. Clin Cancer Res 2003, 9(3): III2-III7.

4. Ashktorab H, Smoot DT, Farzanmehr H, Fidelia-Lambert M, Momen $B$, Hylind L, lacosozio-Dononue C, Carethers MJ, Goel A, Boland CR, Giardiello FM: Clinicopathological features and $\mathrm{msi}$ in colorectal cancers from African Americans. Int J Cancer 2005 in press.

5. Gray KD, Ballard BR, Washington MK, Belue R, Grady WM, Chapman WC, Stain SC: Do adverse histopathologic findings in colorectal cancer patients explain disparate outcomes? J Natl Med Assoc 2006, 98(3):348-35I.
6. Moore WE, Moore LH: Intestinal floras of populations that have a high risk of colon cancer. Appl Environ Microbiol 1995, 6I(9):3202-3207.

7. Suzuki K, Mitsuoka T: Increase in faecal nitrosamines in Japanese individuals given a Western diet. Nature 1981, 294(5840):453-456.

8. Lawrence S: Biotech marks time in Q3. Nat Biotechnol 2005, 23(II): 1332 .

9. Hassan MO, Albarwani S, Al Yahyaee S, Al Haddabi S, Rizwi S, Jaffer A, Al-Lawati J, Cai G, Comuzzie AG, Bayoumi RA: A family study in Oman: large, consanguineous, polygamous Omani Arab pedigrees. Community Genet 2005, 8(I):56-60.

10. Tanira MO, Al-Mukhaini MK, Al-Hinai AT, Al Balushi KA, Ahmed IS: Frequency of CYP2C9 genotypes among Omani patients receiving warfarin and its correlation with warfarin dose. Community Genet 2007, 10(I):32-37.

II. Ansari R, Mahdavinia M, Sadjadi A, Nouraie M, Kamangar F, Bishehsari F, Fakheri H, Semnani S, Arshi S, Zahedi MJ, Darvish-Moghadam S, Mansour-Ghanaei F, Mosavi A, Malekzadeh R: Incidence and age distribution of colorectal cancer in Iran: results of a population-based cancer registry. Cancer Lett 2006, 240(I): | 43- 44.

12. Bishehsari F, Mahdavinia M, Malekzadeh R, Verginelli F, Catalano T, Sotoudeh M, Bazan V, Agnese V, Esposito DL, De Lellis L, Semeraro D, Colucci G, Hormazdi M, Rakhshani N, Cama A, Piantelli M, lacobelli S, Russo A, Mariani-Costantini R: Patterns of K-ras mutation in colorectal carcinomas from Iran and Italy (a Gruppo Oncologico dell'Italia Meridionale study): influence of microsatellite instability status and country of origin. Ann Oncol 2006, 17 Suppl 7:vii9l-vii96.

13. Fazeli MS, Adel MG, Lebaschi AH: Colorectal carcinoma: a retrospective, descriptive study of age, gender, subsite, stage, and differentiation in Iran from 1995 to 2001 as observed in Tehran University. Dis Colon Rectum 2007, 50(7):990-995.

14. Nasidze I, Quinque D, Ozturk M, Bendukidze N, Stoneking M: MtDNA and Y-chromosome variation in Kurdish groups. Ann Hum Genet 2005, 69(Pt 4):40I-4I2.

15. Ebert MP, Model F, Mooney S, Hale K, Lograsso J, Tonnes-Priddy L, Hoffmann J, Csepregi A, Rocken C, Molnar B, Schulz HU, Malfertheiner P, Lofton-Day C: Aristaless-like homeobox-4 gene methylation is a potential marker for colorectal adenocarcinomas. Gastroenterology 2006, I3 I(5): 1418-1430.

16. Benson $A B$ 3rd, Ajani JA, Catalano RB, Engelking C, Kornblau SM, Martenson JA Jr., McCallum R, Mitchell EP, O'Dorisio TM, Vokes EE, Wadler S: Recommended guidelines for the treatment of cancer treatment-induced diarrhea. J Clin Oncol 2004, 22(14):2918-2926.

17. Tanaka H, Deng G, Matsuzaki K, Kakar S, Kim GE, Miura S, Sleisenger $\mathrm{MH}, \mathrm{Kim}$ YS: BRAF mutation, CpG island methylator phenotype and microsatellite instability occur more frequently and concordantly in mucinous than non-mucinous colorectal cancer. Int J Cancer 2006, I I 8(I I):2765-277I.

18. Rajagopalan H, Bardelli A, Lengauer C, Kinzler KW, Vogelstein B, Velculescu VE: Tumorigenesis: RAF/RAS oncogenes and mismatch-repair status. Nature 2002, 418(690I):934.

19. Grady WM: Genomic instability and colon cancer. Cancer Metastasis Rev 2004, 23( I-2): I I-27.

20. Grady WM: Molecular basis for subdividing hereditary colon cancer? Gut 2005, 54(I 2): 1676-1678.

2I. Boland CR, Thibodeau SN, Hamilton SR, Sidransky D, Eshleman JR, Burt RW, Meltzer SJ, Rodriguez-Bigas MA, Fodde R, Ranzani GN, Srivastava S: A National Cancer Institute Workshop on Microsatellite Instability for cancer detection and familial predisposition: development of international criteria for the determination of microsatellite instability in colorectal cancer. Cancer Res 1998, 58(22):5248-5257.

22. Wiggers T, Arends JW, Schutte B, Volovics L, Bosman FT: A multivariate analysis of pathologic prognostic indicators in large bowel cancer. Cancer 1988, 6 I(2):386-395.

23. Cravo ML, Fidalgo PO, Lage PA, Albuquerque CM, Chaves PP, Claro I, Gomes T, Gaspar C, Soares JO, Nobre-Leitao C: Validation and simplification of Bethesda guidelines for identifying apparently sporadic forms of colorectal carcinoma with microsatellite instability. Cancer 1999, 85(4):779-785.

24. Domingo E, Niessen RC, Oliveira C, Alhopuro P, Moutinho C, Espin E, Armengol M, Sijmons RH, Kleibeuker JH, Seruca R, Aaltonen LA, Imai K, Yamamoto H, Schwartz S Jr., Hofstra RM: BRAF-V600E is 
not involved in the colorectal tumorigenesis of HNPCC in patients with functional MLHI and MSH2 genes. Oncogene 2005, 24(24):3995-3998.

25. Samowitz WS, Albertsen H, Sweeney C, Herrick J, Caan BJ, Anderson KE, Wolff RK, Slattery ML: Association of smoking, CpG island methylator phenotype, and V600E BRAF mutations in colon cancer. J Natl Cancer Inst 2006, 98(23): I73I-I738.

26. Spring KJ, Zhao ZZ, Karamatic R, Walsh MD, Whitehall VL, Pike T, Simms LA, Young J, James M, Montgomery GW, Appleyard M, Hewett $D$, Togashi K, Jass JR, Leggett BA: High prevalence of sessile serrated adenomas with BRAF mutations: a prospective study of patients undergoing colonoscopy. Gastroenterology 2006, I 3 I(5): | 400-I 407.

27. Brose MS, Volpe P, Feldman M, Kumar M, Rishi I, Gerrero R, Einhorn E, Herlyn M, Minna J, Nicholson A, Roth JA, Albelda SM, Davies H, Cox C, Brignell G, Stephens P, Futreal PA, Wooster R, Stratton MR, Weber BL: BRAF and RAS mutations in human lung cancer and melanoma. Cancer Res 2002, 62(23):6997-7000.

28. Davies H, Bignell GR, Cox C, Stephens P, Edkins S, Clegg S, Teague J, Woffendin H, Garnett MJ, Bottomley W, Davis N, Dicks E, Ewing R, Floyd Y, Gray K, Hall S, Hawes R, Hughes J, Kosmidou V, Menzies A, Mould C, Parker A, Stevens C, Watt S, Hooper S, Wilson R, Jayatilake $\mathrm{H}$, Gusterson BA, Cooper C, Shipley J, Hargrave D, Pritchard-Jones K, Maitland N, Chenevix-Trench G, Riggins GJ, Bigner DD, Palmieri G, Cossu A, Flanagan A, Nicholson A, Ho JW, Leung SY, Yuen ST, Weber BL, Seigler HF, Darrow TL, Paterson H, Marais R, Marshall CJ, Wooster R, Stratton MR, Futreal PA: Mutations of the BRAF gene in human cancer. Nature 2002, 417(6892):949-954.

29. Konishi K, Takimoto M, Kaneko K, Makino R, Hirayama Y, Nozawa $\mathrm{H}$, Kurahashi T, Kumekawa $Y$, Yamamoto T, Ito H, Yoshikawa N, Kusano M, Nakayama K, Rembacken BJ, Ota H, Imawari M: BRAF mutations and phosphorylation status of mitogen-activated protein kinases in the development of flat and depressedtype colorectal neoplasias. $\mathrm{Br}$ J Cancer 2006, 94(2):3II-3I7.

30. Jass JR: Classification of colorectal cancer based on correlation of clinical, morphological and molecular features. Histopathology 2007, 50(I): I I3-130.

31. Gafa R, Maestri I, Matteuzzi M, Santini A, Ferretti S, Cavazzini L, Lanza G: Sporadic colorectal adenocarcinomas with high-frequency microsatellite instability. Cancer 2000, 89(I0):2025-2037.

32. Risio M, Reato G, di Celle PF, Fizzotti M, Rossini FP, Foa R: Microsatellite instability is associated with the histological features of the tumor in nonfamilial colorectal cancer. Cancer Res 1996, 56(23):5470-5474.

33. Jass JR, Do KA, Simms LA, lino H, Wynter C, Pillay SP, Searle J, Radford-Smith G, Young J, Leggett B: Morphology of sporadic colorectal cancer with DNA replication errors. Gut 1998 42(5):673-679.

34. Fleisher AS, Esteller M, Wang S, Tamura G, Suzuki H, Yin J, Zou TT, Abraham JM, Kong D, Smolinski KN, Shi YQ, Rhyu MG, Powell SM, James SP, Wilson KT, Herman JG, Meltzer SJ: Hypermethylation of the hMLHI gene promoter in human gastric cancers with microsatellite instability. Cancer Res 1999, 59(5): 1090-1095.

35. Deng G, Chen A, Hong J, Chae HS, Kim YS: Methylation of CpG in a small region of the hMLHI promoter invariably correlates with the absence of gene expression. Cancer Res 1999, 59(9):2029-2033.

36. Yanagisawa $Y$, Akiyama $Y$, lida S, Ito E, Nomizu T, Sugihara K, Yuasa $\mathrm{Y}$, Maruyama K: Methylation of the hMLHI promoter in familial gastric cancer with microsatellite instability. Int J Cancer 2000, 85(I):50-53.

37. Miyakura Y, Sugano K, Konishi F, Ichikawa A, Maekawa M, Shitoh K, Igarashi S, Kotake K, Koyama $Y$, Nagai H: Extensive methylation of $\mathrm{hMLHI}$ promoter region predominates in proximal colon cancer with microsatellite instability. Gastroenterology 200I, I2I(6): 1300-1309.

38. Satia JA, Keku T, Galanko JA, Martin C, Doctolero RT, Tajima A, Sandler RS, Carethers JM: Diet, lifestyle, and genomic instability in the North Carolina Colon Cancer Study. Cancer Epidemiol Biomarkers Prev 2005, 14(2):429-436.

39. Slattery ML, Curtin K, Sweeney C, Levin TR, Potter J, Wolff RK, Albertsen H, Samowitz WS: Diet and lifestyle factor associations with CpG island methylator phenotype and BRAF mutations in colon cancer. Int / Cancer 2007, I 20(3):656-663.
40. Longacre TA, Fenoglio-Preiser CM: Mixed hyperplastic adenomatous polyps/serrated adenomas. A distinct form of colorectal neoplasia. Am J Surg Pathol 1990, I4(6):524-537.

4I. Sawhey MS, Farrar WD, Gudiseva S, Nelson DB, Lederle FA, Rector $\mathrm{TS}$, Bond $\mathrm{JH}$ : Microsatellite instability in interval colon cancers. Gastroenterology 2006, I 3 | (6): 1700-1705.

42. Tahir MA, Balamurugan K, Tahir UA, Amjad M, Awin MB, Chaudhary OR, Hamby JE, Budowle B, Herrera RJ: Allelic distribution of nine short tandem repeat (STR), HLA-DQAI, and polymarker loci in an Omani sample population. Forensic Sci Int 2000, 109(2):8I-85.

43. Cheung $\mathrm{KH}$, Osier MV, Kidd JR, Pakstis Al, Miller PL, Kidd KK ALFRED: an allele frequency database for diverse populations and DNA polymorphisms. Nucleic Acids Res 2000, 28(I):36I-363.

44. O'Leary CA: The Kurds of Iraq: Recent History, Future Prospects . 2002, 6(4):

45. Durroei SR: Kurdish: An Indo-European Language . 1998.

46. Ko JM, Cheung MH, Wong CM, Lau KW, Tang CM, Kwan MW, Lung ML: Ki-ras codon 12 point mutational activation in Hong Kong colorectal carcinoma patients. Cancer Lett 1998, 134(2):169-176.

47. Chang SC, Lin JK, Yang SH, Wang HS, Li AF, Chi CW: Relationship between genetic alterations and prognosis in sporadic colorectal cancer. Int J Cancer 2006, I I 8(7): I 72 I- I 727.

48. Carethers JM, Chauhan DP, Fink D, Nebel S, Bresalier RS, Howell SB, Boland CR: Mismatch repair proficiency and in vitro response to 5-fluorouracil. Gastroenterology 1999, I I 7(1):|23-|3|.

Publish with Bio Med Central and every scientist can read your work free of charge

"BioMed Central will be the most significant development for disseminating the results of biomedical research in our lifetime. "

Sir Paul Nurse, Cancer Research UK

Your research papers will be:

- available free of charge to the entire biomedical community

- peer reviewed and published immediately upon acceptance

- cited in PubMed and archived on PubMed Central

- yours - you keep the copyright
BiolMedcentral 